\title{
A Dual Stable Isotope Tracer Method for the Measurement of Surfactant Disaturated- Phosphatidylcholine Net Synthesis in Infants with Congenital Diaphragmatic Hernia
}

\author{
PAOLA E. COGO, LUC J.I. ZIMMERMANN, GIOVANNA VERLATO, PAOLA MIDRIO, \\ ANTONELLA GUCCIARDI, CARLO ORI, AND VIRGILIO P. CARNIELLI
}

\begin{abstract}
Department of Pediatrics [P.E.C., G.V., A.G., P.M.] Department of Pharmacology, Anaesthesia and Critical Care [C.O.], University of Padova, 35128 Padova, Italy; Department of Pediatrics [L.J.I.Z.], Maastricht University, 6202 AZ Maastrict, The Netherlands; and Division of Neonatal Medicine [V.P.C.], Ospedale Salesi, 60123 Ancona, Italy
\end{abstract}

\section{ABSTRACT}

The aim of the study was to measure for the first time in humans surfactant disaturated-phosphatidylcholine (DSPC) net synthesis and kinetics by using a novel, dual stable isotope tracer approach. Ten infants with congenital diaphragmatic hernia $[\mathrm{CDH}$; birth weight, $3.4 \pm 0.2$; gestational age, $39.8 \pm 0.4 \mathrm{wk}]$ and 6 age-matched control subjects with no lung disease (birth weight, 3.2 $\pm 0.3 \mathrm{~kg}$; gestational age, $39.1 \pm 1.1 \mathrm{wk})$, all of whom were admitted to the neonatal intensive care unit (Padua, Italy), were studied. All infants received simultaneously an intratracheal (carbon-13 dipalmitoyl-phosphatidylcholine) and an i.v. (deuterated palmitic acid) stable isotope tracer. Isotopic enrichment curves of DSPC from sequential tracheal aspirates were analyzed by mass spectrometry. DSPC kinetic data were expressed as mean \pm SEM and compared by the Mann-Whitney test. DSPC net synthesis from plasma palmitate was nearly identical in infants with $\mathrm{CDH}$ and control subjects $(8.6 \pm$ 2.2 and $\left.8.1 \pm 1.5 \mathrm{mg} \cdot \mathrm{kg}^{-1} \cdot \mathrm{d}^{-1} ; P=0.7\right)$. DSPC apparent pool size was $36.7 \pm 7.5$ and $58.5 \pm 9.1 \mathrm{mg} / \mathrm{kg}(P=0.07)$ and half-life was $26.7 \pm 4.5$ and $50.3 \pm 9.7 \mathrm{~h}(P=0.03)$ in infants with $\mathrm{CDH}$ and control subjects, respectively. Both DSPC turnover and percentage of catabolism/recycling significantly correlated with duration of mechan- ical ventilation. In conclusion, the measurements of net DSPC synthesis and catabolism/recycling were reported for the first time in humans. Mean net DSPC synthesis was $\sim 8 \mathrm{mg} \cdot \mathrm{kg}^{-1} \cdot \mathrm{d}^{-1}$. No significant differences were found between control subjects and infants with $\mathrm{CDH}$. DSPC turnover was faster in infants with $\mathrm{CDH}$, presumably reflecting an increased DSPC catabolism/recycling. Whether this may ultimately lead to a secondary surfactant deficiency in infants with $\mathrm{CDH}$ is still to be ascertained. (Pediatr Res 56: 184-190, 2004)

\[ \begin{array}{c}\text { Abbreviations } \\ \text { CDH, congenital diaphragmatic hernia }\end{array} \]
DPPC, di-palmitoyl-phosphatidylcholine
DSPC, disaturated-phosphatidylcholine
ECMO, extracorporeal membrane oxygenation
Fo
FSR, fraction of inspired oxygen
$\mathbf{P}_{\mathbf{A}} \mathbf{O}_{2}$, alveolar oxygen pressure
Pao $_{2}$, arterial oxygen pressure
SP-A, surfactant protein A

tions in amniotic fluid have been reported in human $\mathrm{CDH}$ pregnancies after $34 \mathrm{wk}$ of gestation compared with uncomplicated pregnancies (5). Data from human $\mathrm{CDH}$ autopsies showed that DSPC content is markedly lower in the affected lung compared with the contralateral side and with control lungs (6). However, similar concentrations of PC, phosphatidylglycerol, and lecithin/sphingomyelin ratios in bronchoalveolar lavage have been recently reported in infants with $\mathrm{CDH}$ and in age-matched control infants with severe respiratory failure (7).

We recently devised new methods to measure surfactant kinetics and apparent pool size in vivo in humans by means of stable isotopes $(8-11)$. These methods are suitable for the 
study of surfactant in humans. In the first study on human $\mathrm{CDH}$, we measured DSPC fractional synthesis rate (FSR) and turnover in vivo in infants with $\mathrm{CDH}$ using i.v. palmitic acid as a tracer (12). DSPC FSR did not differ between infants with $\mathrm{CDH}$ and control subjects, whereas the amount of DSPC recovered from tracheal aspirates was significantly lower in infants with $\mathrm{CDH}$. FSR represents the percentage of DSPC synthesized per unit time (day) from a given metabolic precursor (plasma palmitic acid). It is noteworthy that the lower the DSPC pool size, the lower the net DSPC synthesis at any given DSPC FSR. At that stage, no estimation of DSPC pool size was feasible; therefore, we could not calculate the net amount of DSPC produced (13). We have also measured DSPC half-life and apparent pool size in vivo in humans by the intratracheal administration of a stable isotope-labeled phospholipid tracer $(11,14,15)$. By applying this method to a separate group of newborns with $\mathrm{CDH}$, we found that apparent DSPC pool size was significantly lower and DSPC half-life and turnover were significantly faster in newborns with $\mathrm{CDH}$ compared with age-matched control subjects (13).

Total PC half-life and its apparent pool size were measured by Janssen et al. in eight newborns who had $\mathrm{CDH}$ and were treated with extracorporeal membrane oxygenation (ECMO) and compared with seven infants who had meconium aspiration syndrome and also were on ECMO and with a mixed group of six term newborns (two with $\mathrm{CDH}$, two with meconium aspiration syndrome, and two with major neurologic issues) who were not on ECMO (16). Total PC half-life and apparent pool size were not different among the three study groups. Neither in the study by Cogo et al. (13) nor in the work by Janssen et al. (16) could we obtain information on DSPC net synthesis. In the present study, we report on a novel dual tracer technique that allowed us to estimate the net DSPC synthesis, i.e. the absolute amount of DSPC produced per day. We performed these measurements in infants with $\mathrm{CDH}$ and in age-matched control infants with no lung disease. We tested the feasibility of the dual tracer approach, and we asked the clinical question of whether the alterations of surfactant DSPC in newborns with $\mathrm{CDH}$ and respiratory failure $(5,12,13)$ are caused by an impaired DSPC net synthesis or by a faster DSPC catabolism/recycling or by a combination of both.

\section{METHODS}

Subjects. Surfactant kinetics was studied in mechanically ventilated infants with $\mathrm{CDH}$ (CDH group) and in control newborns who had normal lungs and were also on mechanical ventilation. All infants enrolled in the study were admitted to the neonatal intensive care unit (Padua, Italy) from July 2000 to December 2002. Because of the new method, these patients were not included in any of the $\mathrm{CDH}$ papers published by our group $(12,13,16)$. The protocol was approved by the local ethics committee, and written informed consent was obtained from both parents.

All infants with $\mathrm{CDH}$ had respiratory failure that required endotracheal intubation. Control subjects were full-term newborn infants with 1) no history of lung disease, 2) normal chest radiograph, and 3) fraction of inspired oxygen $\left(\mathrm{FIO}_{2}\right)<30 \%$ before and at any time during the study period. They were on mechanical ventilation for abdominal or airway malformations or neurologic impairment. Inclusion criteria for both groups were 1) presence of arterial (right radial in $\mathrm{CDH}$ ) and venous lines for clinical monitoring, 2) no evidence of infection, 3) no exogenous surfactant administered, and 4) written informed parental consent.

Protocol. All infants with $\mathrm{CDH}$ were ventilated with highfrequency oscillatory ventilation from birth. Time of surgery was postponed until hemodynamic stability was achieved. Control subjects were on conventional ventilation. Ventilator parameters and gas exchange were recorded every $6 \mathrm{~h}$, and arterial oxygen pressure $\left(\mathrm{PaO}_{2}\right) / \mathrm{FIO}_{2}$ ratio, $\mathrm{PaO}_{2} /$ alveolar oxygen pressure $\left(\mathrm{P}_{\mathrm{A}} \mathrm{O}_{2}\right)$ ratio, $\mathrm{PaO}_{2} / \mathrm{P}_{\mathrm{A}} \mathrm{O}_{2}$ gradient, and oxygenation index were calculated.

At study time 0, all infants received an endotracheal tracer dose of $5 \mathrm{mg} / \mathrm{kg}$ of di-palmitoyl-phosphatidylcholine (DPPC) labeled with [U- ${ }^{13} \mathrm{C}$-palmitic acid] (Martek Biosciences, Columbia, MD, U.S.A.) $(11,17)$ mixed with a $0.3 \mathrm{~mL}(\sim 10 \mathrm{mg}$ of DSPC) of porcine surfactant (Curosurf; Chiesi, Parma, Italy) as vehicle. At the same time, a 24-h constant i.v. infusion of albumin-bound $16,16,16{ }^{2} \mathrm{H}$ palmitic acid (CIL, Andover, MA, U.S.A.) was started to trace endogenous surfactant (10).

Measurements. Tracheal aspirates were collected before the tracer administration, every $6 \mathrm{~h}$ until $72 \mathrm{~h}$, and every $12 \mathrm{~h}$ thereafter until extubation. Clinical and analytical methods have been published in detail elsewhere $(10,11)$. Briefly, the airways were suctioned with $0.5 \mathrm{~mL}$ of $0.9 \%$ saline injected through the endotracheal tube. The tracheal aspirate was kept at $4^{\circ} \mathrm{C}$ for no longer than $3 \mathrm{~h}$ and was brought to a final volume of $2 \mathrm{~mL}$ with $0.9 \%$ saline. The sample was gently vortexed for $1 \mathrm{~min}$ and centrifuged at $200 \times g$ for $10 \mathrm{~min}$. The supernatant was recovered and kept at $-20^{\circ} \mathrm{C}$ until analysis. The enrichments of ${ }^{13} \mathrm{C}$ and ${ }^{2} \mathrm{H}$ DSPC palmitic acid obtained from tracheal aspirates were measured by gas chromatographyisotope ratio mass spectrometry (Delta XL Thermoquest, Rodano, Italy) $(18,19)$. Results were expressed as mole percent excess (10). The mole percent excess represents the increase in isotopic enrichment above baseline after tracer(s) administration of ${ }^{13} \mathrm{C}$ and ${ }^{2} \mathrm{H}$, after complete combustion and pyrolysis, respectively.

Blood $(0.6 \mathrm{~mL})$ was drawn at study times $0,3,6,12,18$, and $24 \mathrm{~h}$ to determine the isotopic enrichment of palmitic acid in plasma free fatty acids $(8,10)$ by a quadruple mass spectrometer using the negative chemical ionization mode (Voyager; Thermoquest, Rodano, Italy) $(8,12)$.

Surfactant kinetic parameters. DSPC half-life and apparent pool size were calculated from the ${ }^{13} \mathrm{C}$-DSPC enrichment decay curve over time $(11,14,20,21)$. The amount of DSPC administered with tracer and the vehicle was quantified by gas chromatography $(11,13,15)$ and subtracted from the total apparent DSPC pool size of each study infant.

DSPC FSR, secretion time, and peak time were measured from the deuterium isotopic enrichment of DSPC palmitic acid (10). DSPC synthesis, expressed in milligrams per kilogram of body weight per day, was obtained by multiplying DSPC FSR by the DSPC apparent pool size. Percentage of DSPC catabolism/recycling was calculated as follows: (DSPC half-life in 
$24 \mathrm{~h}$ - DSPC synthesis)/DSPC apparent pool size. It represents the percentage of DSPC pool that is either lost or recycled per day. Figure 1 depicts a model diagram explaining the kinetic variables that were measured and those that were derived.

Data analysis. This study should be regarded as a nonrandomized pilot study. Net DSPC synthesis (absolute synthesis rate) was the main study variable from which sample size should have been calculated. However, because this is a novel measurement, no power analysis could be performed. Data are presented as mean \pm SEM. Group comparisons were calculated by Mann Whitney test. Correlations were obtained by Pearson correlation. The level of significance was $P<0.05$. (SPSS 10.0 for Windows 98).

\section{RESULTS}

We studied 16 mechanically ventilated newborn infants; 10 infants had $\mathrm{CDH}$, and 6 infants with no lung disease served as control subjects. Clinical characteristics of the two study groups are reported in Table 1. Demographics were similar between the two groups, whereas ventilator parameters were significantly different as expected by study design (Table 1). Four infants' CDH was diagnosed prenatally, all before $26 \mathrm{wk}$ gestational age. Two of the 10 infants' $\mathrm{CDH}$ were right sided, and 8 left sided. No CDH study infants had chromosomal or other congenital associated abnormalities. They all were sedated, paralyzed, and ventilated on high-frequency oscillatory ventilation since birth, with no signs of infection during the study period. Two (20\%) infants with $\mathrm{CDH}$ died before hospital discharge. Causes of death were lung hypoplasia (1 infant) and sepsis (1 infant); none of the survivors were oxygen dependent at hospital discharge.
All six control subjects required intermittent positive pressure ventilation: two for airway or oral malformations (congenital subglottic stenosis and palatoschisis) while waiting for surgery, two for abdominal surgery (omphalocele and hepatic hemangioma), and two for neuromuscular impairment (birth asphyxia). No control subjects had evidence of infection during the study period. One control infant died before hospital discharge. Cause of death was severe neurologic failure as a result of hypoxic-ischemic injury. All infants with $\mathrm{CDH}$ and control infants who did not survive to hospital discharge died after the study was completed.

In all study infants, the isotopic enrichment of ${ }^{2} \mathrm{H}$ palmitic acid in plasma free fatty acids was on steady state (linear regression slopes of the enrichment values versus time were not significantly different from zero) between study hours 3 and 24 (data not shown). Plasma free palmitate concentrations were also stable during the study period. A significant incorporation of i.v. infused ${ }^{2} \mathrm{H}$-palmitic acid was measurable in surfactant DSPC. All 16 study infants exhibit a bi-exponential decay curve of ${ }^{13} \mathrm{C}$ DSPC after the endotracheal tracer administration. Figure 2 depicts the isotopic enrichment curves obtained from an index infants with $\mathrm{CDH}$ (Fig. $2 A$ ) and one control subject (Fig. 2B).

Data obtained from the intratracheal tracer. DSPC half-life was $26.7 \pm 4.5$ and $50.3 \pm 9.7 \mathrm{~h}(P=0.03)$, apparent pool size was $36.7 \pm 7.5$ and $58.5 \pm 9.1 \mathrm{mg} / \mathrm{kg}(P=0.07)$, and turnover was $0.8 \pm 0.1$ and $1.4 \pm 0.3 / \mathrm{d}(P=0.03)$ in infants with $\mathrm{CDH}$ and control subjects, respectively (Table 2).

Data obtained from the i.v. tracer. FSR from plasma free palmitate was $21 \pm 3 \%$ versus $15 \pm 4 \% / \mathrm{d}$, secretion time was $10.4 \pm 0.2$ versus $12.0 \pm 1.3 \mathrm{~h}$, and peak time was $54 \pm 5$

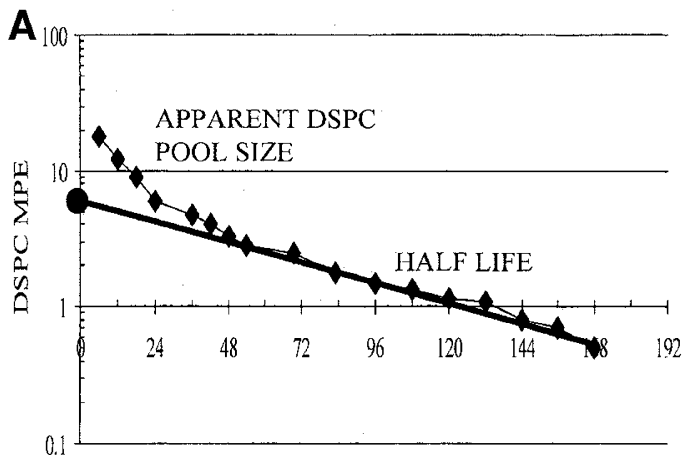

\section{Measured kinetic data}

-Intratracheally labelled

-DSPC half-life

-Apparent DSPC pool size (PS)

-Intravenously labelled

-DSPC FSR

-DSPC Secretion time

-DSPC Peak time

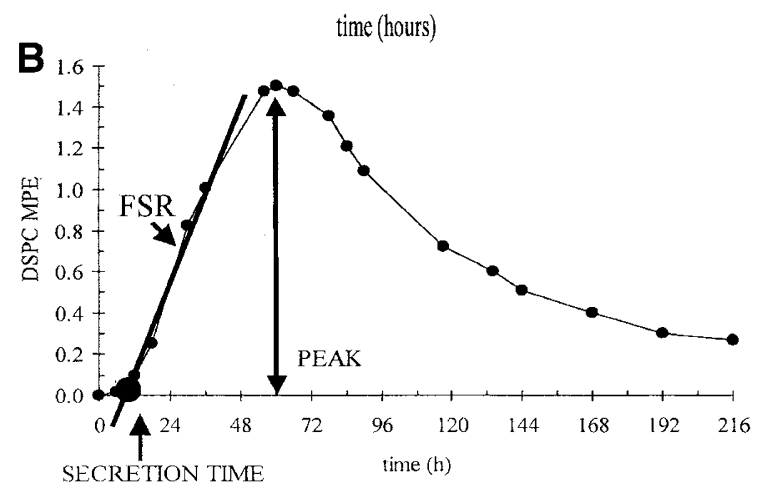

\section{Calculated kinetic data}

-DSPC synthesis $=$ DSPC FSR $x$ PS

-DSPC catabolism-recycling =

(DSPC half-life-DSPC synthesis)

PS

Figure 1. (A) The kinetic variables that were measured directly from the isotopic enrichment curves over time of all study infants. $(B)$ The formulas of the variables derived from the measured kinetic data. 
Table 1. Demographics and clinical characteristic of the study infants

\begin{tabular}{lccc}
\hline & $\begin{array}{c}\mathrm{CDH} \\
(n=10)\end{array}$ & $\begin{array}{c}\text { Controls } \\
(n=6)\end{array}$ & $P$ \\
\hline Birth weight (kg) & $3.4 \pm 0.2$ & $3.2 \pm 0.3$ & 0.4 \\
Gestational age (wk) & $39.8 \pm 0.4$ & $39.1 \pm 1.1$ & 0.5 \\
Sex (M/F) & $5 / 5$ & $3 / 3$ & 0.7 \\
Age at the study (h) & $56 \pm 15$ & $115 \pm 31$ & 0.15 \\
Age at the surgery (d) & $4.3 \pm 1.6$ & $/$ & $/$ \\
Intubation time (d) & $13 \pm 3$ & $11 \pm 8$ & 0.8 \\
Survival (\%) & $80 \%$ & $87 \%$ & 0.4 \\
Mean airway pressure $\left(\mathrm{cm} \mathrm{H}_{2} \mathrm{O}\right)$ & $10.7 \pm 0.8$ & $3.2 \pm 0.9$ & 0.007 \\
$\mathrm{~A}-\mathrm{a} \mathrm{Po}_{2}$ gradient $(\mathrm{mmHg})$ & $317 \pm 36$ & $91 \pm 53$ & 0.01 \\
$\mathrm{PaO}_{2} / \mathrm{FIO}_{2}$ ratio & $178 \pm 18$ & $333 \pm 20$ & 0.007 \\
$\mathrm{Oxygenation}$ index & $10 \pm 2$ & $2 \pm 1$ & 0.002 \\
$\mathrm{PaO}_{2} / \mathrm{PaO}_{2}$ ratio & $0.39 \pm 0.06$ & $0.90 \pm 0.03$ & 0.001 \\
\hline
\end{tabular}

versus $59 \pm 5 \mathrm{~h}$ in infants with $\mathrm{CDH}$ and control subjects, respectively. These DSPC kinetic parameters were not significantly different between the two groups (Table 2). Five infants with $\mathrm{CDH}$ and four control infants were extubated before the descending part of the i.v. tracer $\left({ }^{2} \mathrm{H}\right.$ palmitate) was recordable. Thus, group means of endogenous DSPC half-life could not be calculated reliably.

Data obtained combining information of the two tracers. Mean DSPC net synthesis from plasma free palmitate (DSPC absolute synthesis rate) was similar in the two groups: $8.6 \pm$ 2.2 versus $8.1 \pm 1.5 \mathrm{mg} \cdot \mathrm{kg}^{-1} \cdot \mathrm{d}^{-1}$ in infants with $\mathrm{CDH}$ versus control subjects, respectively. The percentage of DSPC
Table 2. DSPC kinetic parameters in newborn infants with $C D H$ and severe respiratory failure and age-matched controls subjects

\begin{tabular}{lccl}
\hline & $\begin{array}{c}\text { CDH } \\
(n=10)\end{array}$ & $\begin{array}{c}\text { Controls } \\
(n=6)\end{array}$ & $P$ \\
\hline FSR (\%/d) & $21 \pm 3$ & $15 \pm 4$ & 0.06 \\
Secretion time (h) & $10.4 \pm 0.2$ & $12.0 \pm 1.3$ & 0.7 \\
Peak time (h) & $54 \pm 5$ & $59 \pm 5$ & 0.3 \\
Half-life from intratracheal ${ }^{13} \mathrm{C}$ DPPC (h) & $26.7 \pm 4.5$ & $50.3 \pm 9.7$ & 0.03 \\
Apparent pool size $(\mathrm{mg} / \mathrm{kg})$ & $36.7 \pm 7.5$ & $58.5 \pm 9.1$ & 0.07 \\
Turnover $(/ \mathrm{d})$ & $0.8 \pm 0.1$ & $1.4 \pm 0.3$ & 0.03 \\
Net synthesis $\left(\mathrm{mg} \cdot \mathrm{kg}^{-1} \cdot \mathrm{d}^{-1}\right)$ & $8.6 \pm 2.2$ & $8.1 \pm 1.5$ & 0.7 \\
Catabolism/recycling $(\%)$ & $40 \pm 10$ & $20 \pm 5$ & 0.18 \\
\hline
\end{tabular}

catabolism/recycling was $40 \pm 10 \%$ (range, $0.2-84 \%$ ) in the $\mathrm{CDH}$ group and $20 \pm 5 \%$ (range, $0.2-35 \%$ ) in control subjects. Group mean was 2-fold higher in infants with $\mathrm{CDH}$ than in control subjects, but the difference was not statistically significant $(P=0.18)$.

In infants with $\mathrm{CDH}$, we found a significant negative correlation between duration of mechanical ventilation and DSPC turnover $(R=-0.86, P=0.03)$, i.e. patients who were the longest on the ventilator had highest DSPC turnover. A positive correlation was also found in infants with $\mathrm{CDH}$ between duration of mechanical ventilation and percentage of catabolism/recycling $(R=0.85, P=0.03$; Fig. 3$)$ and between DSPC turnover and mean $\mathrm{PaO}_{2} / \mathrm{FIO}_{2}$ ratio $(R=0.6, P=0.05)$ and mean $\mathrm{PaO}_{2} / \mathrm{P}_{\mathrm{A}} \mathrm{O}_{2}(R=0.7, P=0.04)$.
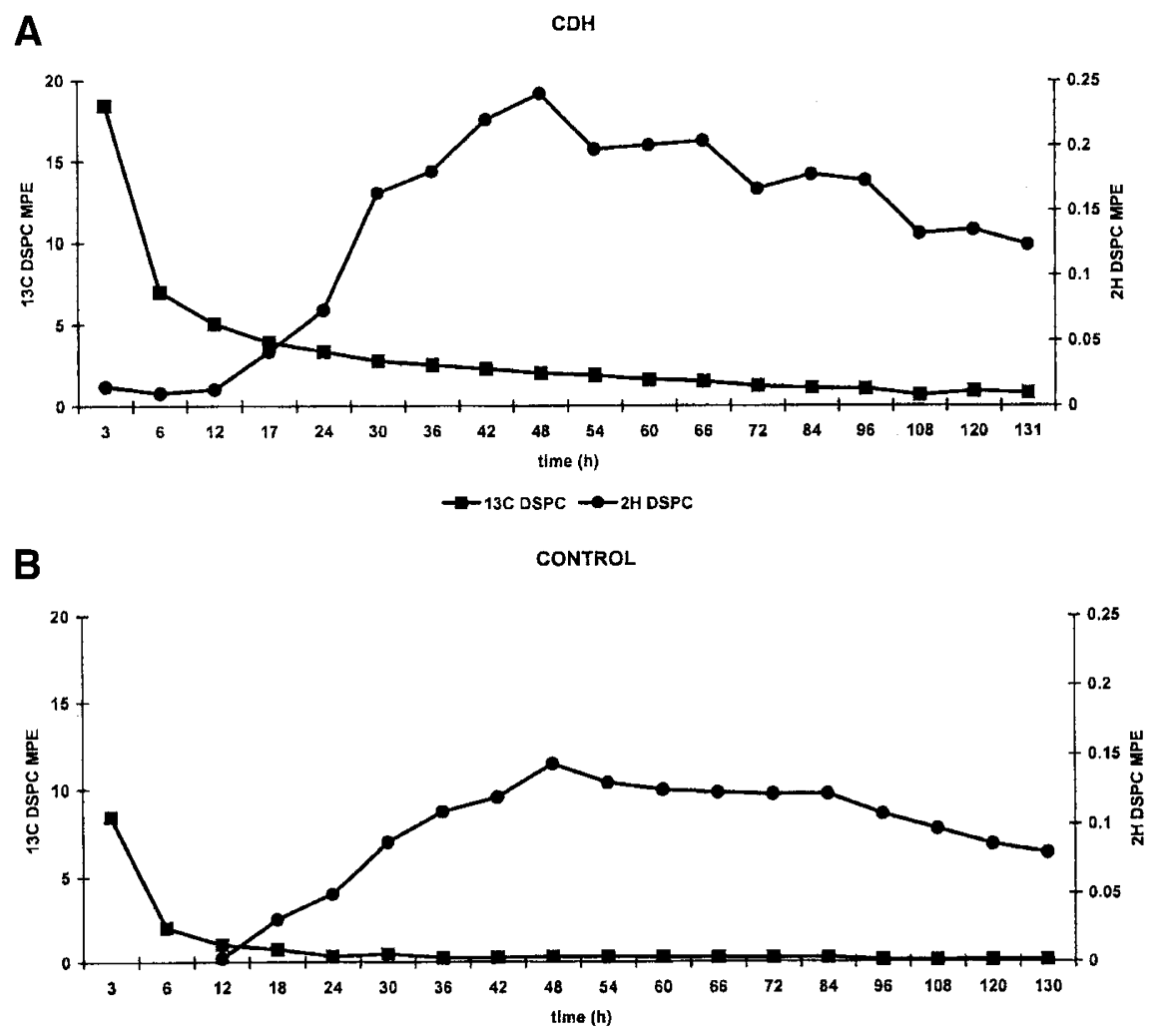

Figure 2. Isotopic enrichment curves of ${ }^{13} \mathrm{C}$ ( $\square$ and $y$ axis on the left) and ${ }^{2} \mathrm{H}(\boldsymbol{a}$ and $y$ axis on the right) of DSPC palmitate obtained from sequential tracheal aspirates in an infant with $\mathrm{CDH}(A)$ and a control newborn $(B)$. The intratracheal tracer $\left({ }^{13} \mathrm{C}\right.$ di-palmitoyl-phosphatidylcholine $)$ and the i.v. tracer $\left({ }^{2} \mathrm{H}\right.$ palmitic acid) both were started simultaneously at study time 0 . We calculated DSPC FSR, secretion time, and peak time from the isotopic enrichment curves of ${ }^{2} \mathrm{H}$ palmitate-DSPC and DSPC half-life, apparent pool size, and turnover from the bi-exponential decay curve of the ${ }^{13} \mathrm{C}$ palmitate-DSPC over time. 


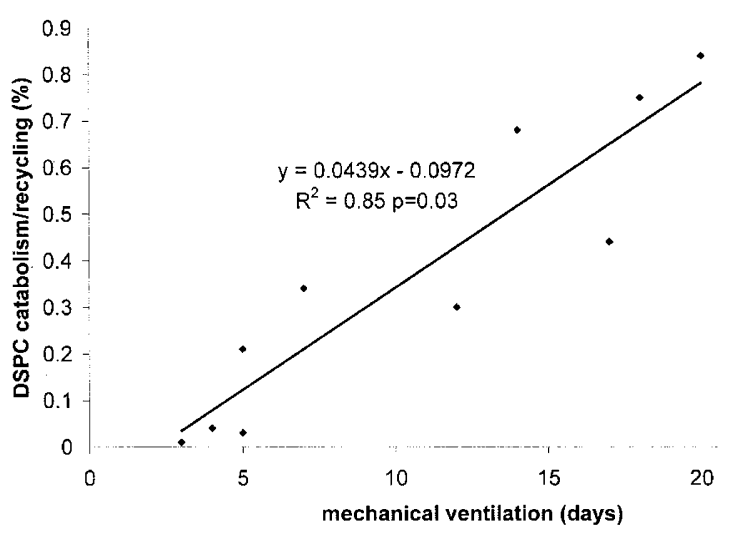

Figure 3. Significant correlation between the percentage of DSPC catabolized or recycled and the duration of mechanical ventilation in infants with $\mathrm{CDH}$. A $25 \%$ increase in DSPC recycling was associated in our $\mathrm{CDH}$ group of infants with 8 additional days on the ventilator $\left(\mathrm{y}=0.0439 \mathrm{x}, \mathrm{R}^{2}=0.85, P=0.03\right)$.

\section{DISCUSSION}

Unlike in previous studies by our group, we report here on 1) a novel dual tracer approach for the estimation of the surfactant DSPC net synthesis in vivo in humans and on 2) the clinical finding that DSPC net synthesis was not different between infants with $\mathrm{CDH}$ and control newborns with normal lungs. Surfactant kinetics, including net synthesis, has been measured by using multiple radiolabels in animal models, where lungs can be completely lavaged when the animals are killed to quantify surfactant alveolar and tissue pools (22-25). The validity of this model to study surfactant kinetics in vivo was demonstrated by several authors with radioactive isotopes $(24,25)$. More recently, surfactant kinetics was studied in vivo in humans by means of stable isotope technology $(8-12,15)$. Kinetic studies with radioactive as well as stable isotopic tracers are based on the same assumptions that we and others have discussed extensively in previous publications $(11,12,20)$. The most obvious advantage of stable isotope technology is that stable isotopes are nonradioactive and not hazardous to humans. Because of ethical constraints and the inevitable limitations to sample collection in humans, the kinetic parameters calculated in vivo by stable isotopes may differ from the direct measurement in lung tissue or in alveolar lavage fluid. Advantages and disadvantages of stable isotope studies were discussed eloquently in a recent editorial (26). Kinetic studies in animal models with radioactive traces may also have limitations. Determination of alveolar surfactant obtained by repeated alveolar washes carries the risk of incomplete recovery, which may be more pronounced in sicker lungs. Measurements of tissue-associated DSPC carries the risk of measuring "nonsurfactant DSPC," which is present in interstitial tissue, blood vessels, non-type II cells, and inflammatory cells (unpublished data). Nevertheless, we found a fair correspondence between DSPC pool size measurements by stable isotopes and direct DSPC pool size measurements in preterm baboons with developing bronchopulmonary dysplasia (14). Moreover, human studies, as opposed to animal studies, have the major advantage of studying the human disease. Conversely, animal models may or may not mimic the human condition, especially if chemical teratogens are used as is the case of the rat $\mathrm{CDH}$ model induced by nitrofen.

In this article, we have further studied surfactant kinetics in human $\mathrm{CDH}$, and we believe that the dual tracer technique described in this article better matches the method and results of animal studies. DSPC absolute synthesis rate is the product of DSPC FSR and DSPC pool size. It represents the net incorporation of a single surfactant precursor (palmitic acid, e.g.) into a known DSPC pool size and therefore the net DSPC amount produced from a given precursor per unit of time. In this pilot study, we found that net DSPC synthesis from plasma palmitate was nearly identical in the two study groups, strongly suggesting that $\mathrm{CDH}$ lungs are capable of synthesizing similar amounts of DSPC to normal lungs. On the basis of these pilot data, we calculated that a much larger study, of at least 280 infants, would be needed to demonstrate a statistically significant DSPC net synthesis in infants with $\mathrm{CDH}$ versus control subjects. Even if such a study were to be performed, the difference, if confirmed, would likely be biologically/clinically insignificant.

We believe that the 10 infants with $\mathrm{CDH}$ who were enrolled in the present study represent an unselected $\mathrm{CDH}$ population, thus including the most severe as well as milder cases. It is noteworthy that all patients were recruited consecutively and that our neonatal intensive care unit is a tertiary referral center as well as an ECMO center, where all infants with $\mathrm{CDH}$ from our region are referred for treatment. The only infants with CDH whom we did not study from July 2000 to December 2002 were three infants who had multiple malformations and died soon after delivery. We have no data on the percentage of termination of pregnancy for $\mathrm{CDH}$ in our region. Our treatment guidelines include sedation and paralysis, high-frequency ventilation, and delayed surgery aiming to minimize barotraumas to avoid ECMO (27). With this strategy, the overall survival was $\sim 70 \%$ at the time of the study.

Janssen et al. (16) reported on a reduced total PC FSR in infants who had $\mathrm{CDH}$ and required ECMO. This finding could represent a reduced net PC synthesis as a result of type II cell dysfunction in the sickest infants with $\mathrm{CDH}$. An alternative explanation, as it was discussed by Janssen at al., was a reduced "precursor availability" to the alveolar type II cells because of a diminished blood flow to the lungs during ECMO. In view of the previous considerations and given that we found no correlation between DSPC synthesis and clinical severity (present study), we believe that the preserved DSPC net synthesis reported here unlikely results from a greater proportion of mild CDH cases being enrolled by chance in this study.

Whether even higher DSPC synthesis (higher than our measurement in control subjects) can take place in anatomically normal lungs with lung injury or pneumonia was not investigated in this article, and such studies are in progress by our group. The synthesis of other essential surfactant components, such as the surfactant-specific proteins, was also not studied in the present work. Their synthesis could well be impaired in $\mathrm{CDH}$ lungs, and this could cause alterations of surfactant composition and function. This article confirms our previous finding of an $80 \%$ faster DSPC turnover in infants with $\mathrm{CDH}$. 
This could be due to a primary alteration of DSPC metabolism in the hypoplastic CDH lungs or could be secondary to the increased $\mathrm{FIO}_{2}$ and ventilator support required by the sick infants with $\mathrm{CDH}$. All infants with $\mathrm{CDH}$ were on highfrequency ventilation, whereas control subjects were on conventional ventilation. We believe that this difference in ventilation style is unlikely to be the cause of such a profound effect on DSPC kinetics. To our knowledge, there are no published data on surfactant kinetics in $\mathrm{CDH}$ on either high-frequency or conventional ventilation. The only available data are in preterm infants with respiratory distress syndrome by Merchak et al. (28), who found no difference in DSPC kinetics between high-frequency ventilation and conventional ventilation. If high-frequency ventilation had an effect on DSPC half-life, then it would likely reduce or maintain surfactant turnover but not hasten it. We cannot exclude, however, that the higher mean airway pressure and the higher $\mathrm{FIO}_{2}$ required because of the circulatory and respiratory failure of the sick newborns with $\mathrm{CDH}$ may have caused an increased DSPC catabolism and therefore an increased DSPC turnover. Noteworthy is that in the $\mathrm{CDH}$ group, we found a significant correlation between DSPC turnover and main indices of respiratory insufficiency such as the $\mathrm{PaO}_{2} / \mathrm{FIO}_{2}$ ratio and $\mathrm{PaO}_{2} / \mathrm{P}_{\mathrm{A}} \mathrm{O}_{2}$, as well as with the duration of mechanical ventilation. All of these indices were calculated from the preductal $\mathrm{PaO}_{2}$ and therefore are unlikely to be affected by blood mixing at the level of ductus arteriosus, if patent.

A faster DSPC turnover is the consequence of a faster U- ${ }^{13} \mathrm{C}$-palmitic acid-DPPC disappearance from the DSPC pool. Disappearance rate of U- ${ }^{13} \mathrm{C}$-palmitic acid-DPPC reflects the DSPC disappearance rate from lung DSPC. Tracer disappearance can be caused either by an increased DSPC catabolism (loss of stable isotope DPPC molecules) or by an increased deacylation/reacylation pathway (29). In the latter case, the tracer palmitic acid produced by breakdown of DSPC is reincorporated into newly synthesized non-DSPC molecules; thus, it is lost from the DSPC pool.

Under steady-state condition, DSPC disappearance must be equal to DSPC synthesis rate. From the disappearance rate of U- ${ }^{13} \mathrm{C}$-palmitic acid-DPPC, we could calculate the amount of DSPC either catabolized or recycled. We expressed this DSPC amount as percentage of the apparent DSPC pool size, as indicator of tracer losses/recycling. The mean value of the $\mathrm{CDH}$ group was twice as high as the mean value of the control group, but the difference did not reach statistical significance, likely because of the small number of patients and the wide spread of data. A larger number of infants may cause this 2 -fold difference to turn into a statistically significant difference. Interesting is that we found that the infants with $\mathrm{CDH}$, who had the highest DSPC percentage of catabolism/recycling, were the longest on mechanical ventilation $(R=0.86, P=$ $0.03)$. Accordingly, DSPC turnover was faster in infants with $\mathrm{CDH}$ with the longest duration of mechanical ventilation $(R=$ $-0.86, P=0.03)$. A fast DSPC turnover associated with high DSPC recycling likely reflects an increased catabolism of DSPC species. Correlations between amount of DSPC catabolized or recycled and clinical severity or ventilator settings should be confirmed in future studies enrolling a much larger number of patients.

In conclusion we describe here for the first time in vivo in humans a novel method for the measurement of surfactant DSPC net synthesis. By applying this method in newborns with $\mathrm{CDH}$ and severe respiratory failure, we found that $\mathrm{CDH}$ hypoplastic lungs are able to synthesize similar amounts of surfactant DSPC to age-matched control subjects. The infants with the most severe $\mathrm{CDH}$, with persisting respiratory failure, exhibited higher DSPC turnover rates and likely a faster catabolism/recycling of DSPC molecules. Our data suggest that surfactant DSPC alteration in human $\mathrm{CDH}$ is not related to a reduced net DSPC synthesis. Whether other primary or secondary alterations of other surfactant components are present in human $\mathrm{CDH}$ deserves further investigation.

Acknowledgments. We thank all of the nurses of the neonatal intensive care unit, Department of Pediatrics, (Padua, Italy) for their precious contribution in assisting the patients and performing the infusions and the tracheal aspirates.

\section{REFERENCES}

1. Iritani I 1984 Experimental study on embryogenesis of congenital diaphragmatic hernia. Anat Embryol 169:133-139

2. Suen HC, Bloch KD, Donahoe PK 1994 Antenatal glucocorticoid corrects pulmonary immaturity in experimentally induced congenital diaphragmatic hernia in rats. Pediatr Res 35:523-529

3. Utsuki T, Hashizume K, Iwamori M 2001 Impaired spreading of surfactant phospholipids in the lungs of newborn rats with pulmonary hypoplasia as a model of congenital diaphragmatic hernia induced by nitrofen. Biochim Biophys Acta 1531:90-98

4. Mysore MR, Margraf LR, Jaramillo MA, Breed DR, Chau VL, Arevalo M, Moya FR 1998 Surfactant protein A is decreased in a rat model of congenital diaphragmatic hernia. Am J Respir Crit Care Med 157:654-657

5. Moya FR, Thomas VL, Romaguera J, Mysore MR, Maberry M, Bernard A, Freund M 1995 Fetal lung maturation in congenital diaphragmatic hernia. Am J Obstet Gynecol 173:1401-1405

6. Nakamura Y, Yamamoto I, Fukuda S, Hashimoto T 1991 Pulmonary acinar development in diaphragmatic hernia. Arch Pathol Lab Med 115:372-376

7. IJsselstijn H, Zimmermann LJ, Bunt JE, de Jongste JC, Tibboel D 1998 Prospective evaluation of surfactant composition in bronchoalveolar lavage fluid of infants with congenital diaphragmatic hernia and of age-matched controls. Crit Care Med 26:573580

8. Cavicchioli P, Zimmermann LJ, Cogo PE, Badon T, Giordano G, Torresin M, Zacchello F, Carnielli VP 2001 Endogenous surfactant turnover in preterm infants with respiratory distress syndrome studied with stable isotope lipids. Am J Respir Crit Care Med 163:55-60

9. Bunt JE, Zimmermann LJ, Wattimena JL, van Beek RH, Sauer PJ, Carnielli VP 1998 Endogenous surfactant turnover in preterm infants measured with stable isotopes. Am J Respir Crit Care Med 157:810-814

10. Cogo PE, Carnielli VP, Bunt JE, Badon T, Giordano G, Zacchello F, Sauer PJ, Zimmermann LJ 1999 Endogenous surfactant metabolism in critically ill infants measured with stable isotope labeled fatty acids. Pediatr Res 45:242-246

11. Torresin M, Zimmermann LJ, Cogo PE, Cavicchioli P, Badon T, Giordano G, Zacchello F, Sauer PJ, Carnielli VP 2000 Exogenous surfactant kinetics in infant respiratory distress syndrome: a novel method with stable isotopes. Am J Respir Crit Care Med 161:1584-1589

12. Cogo PE, Zimmermann LJ, Rosso F, Tormena F, Gamba P, Verlato G, Baritussio A, Carnielli VP 2002 Surfactant synthesis and kinetics in infants with congenital diaphragmatic hernia. Am J Respir Crit Care Med 166:154-158

13. Cogo PE, Zimmermann LJ, Meneghini L, Mainini N, Bordignon L, Suma V, Buffo M, Carnielli VP 2003 Pulmonary surfactant disaturated-phosphatidylcholine (DSPC) turnover and pool size in newborn infants with congenital diaphragmatic hernia (CDH). Pediatr Res 54:653-658

14. Janssen DJ, Carnielli VP, Cogo PE, Seidner SR, Luijendijk IHI, Wattimena DJL, Jobe AH, Zimmermann LJI 2002 Surfactant phosphatidylcholine half-life and pool size measurements in premature baboons developing bronchopulmonary dysplasia. Pediatr Res 52:724-729

15. Cogo PE, Zimmermann LJ, Pesavento R, Sacchetto E, Burighel A, Rosso F, Badon T, Verlato G, Carnielli VP 2003 Surfactant kinetics in preterm infants on mechanical ventilation who did and did not developed bronchopulmonary dysplasia (BPD). Crit Care Med 31:1532-1538 
16. Janssen DJ, Tibboel D, Carnielli VP, van Emmen E, Luijendijk IH, Darcos Wattimena JL, Zimmermann LJ 2003 Surfactant phosphatidylcholine pool size in human neonates with congenital diaphragmatic hernia requiring ECMO. J Pediatr 142:247252

17. Ikegami M, Jobe A, Duane G 1985 Liposomes of dipalmitoylphosphatidylcholine associate with natural surfactant. Biochim Biophys Acta 835:352-359

18. Carnielli VP, Sulkers EJ, Moretti C, Wattimena JL, Van Goudoever JB, Degenhar HJ, Zacchello F, Sauer PJ 1994 Conversion of octanoic acid into long-chain saturated fatty acids in premature infants fed a formula containing medium-chain triglycerides. Metabolism 43:1287-1292

19. Kelly SD, Parker IG, Sharman M, Dennis MJ 1998 On-line quantitative determination of $2 \mathrm{H} / 1 \mathrm{H}$ isotope ratio in organic and water samples using an elemental analyser coupled to an isotope ratio mass spectrometer. J Mass Spectrom 33:735-738

20. Hallman M, Merritt TA, Pohjavuori M, Gluck L 1986 Effect of surfactant substitution on lung effluent phospholipids in respiratory distress syndrome: evaluation of surfactant phospholipid turnover, pool size, and the relationship to severity of respiratory failure. Pediatr Res 20:1228-1235

21. Griese M, Dietrich P, Reinhardt D 1995 Pharmacokinetics of bovine surfactant in neonatal respiratory distress syndrome. Am J Respir Crit Care Med 152:1050-1054
22. Nicholas TE, Barr HA, Power JH, Jones ME 1990 Uptake of instilled radiolabeled lamellar bodies from alveolar compartment of the rat. Am J Physiol 259:L238 -L246

23. Baritussio A, Carraro R, Bellina L, Rossi A, Bruni R, Pettenazzo A, Enzi G 1985 Turnover of phospholipids isolated from fractions of lung lavage fluid. J Appl Physiol 59:1055-1060

24. Jacobs H, Jobe A, Ikegami M, Conaway D 1983 The significance of reutilization of surfactant phosphatidylcholine. J Biol Chem 258:4159-4165

25. Jacobs H, Jobe A, Ikegami M, Jones S 1982 Surfactant phosphatidylcholine source, fluxes, and turnover times in 3-day-old, 10-day-old, and adult rabbits. J Biol Chem 257:1805-1810

26. Jobe A 2003 Surfactant metabolism in newborns-insights from imprecise measurements. J Pediatr 142:223-224

27. Bohn D 2002 Congenital diaphragmatic hernia. Am J Respir Crit Care Med 166:911-915

28. Merchak A, Janssen DJ, Bohlin K, Patterson BW, Zimmermann LJ, Carnielli VP, Hamvas A 2002 Endogenous pulmonary surfactant metabolism is not affected by mode of ventilation in premature infants with respiratory distress syndrome. J Pediatr 140:693-698

29. Jobe A, Jacobs HC 1984 Catabolism of pulmonary surfactant. In: Robertson B (ed) Pulmonary Surfactant. Elsevier, Amsterdam, pp 271-293 